\title{
Maternal pre-pregnancy body mass index, smoking in pregnancy, and alcohol intake in pregnancy in relation to pubertal timing in the children
}

Nis Brix ${ }^{1,2^{*}}$ (D) Andreas Ernst ${ }^{1,2}$, Lea Lykke Braskhøj Lauridsen', Erik Thorlund Parner ${ }^{3}$, Onyebuchi A. Arah²,4, Jørn Olsen ${ }^{2,5}$, Tine Brink Henriksen ${ }^{6}$ and Cecilia Høst Ramlau-Hansen ${ }^{1}$

\begin{abstract}
Background: Earlier pubertal timing has been observed in many countries. We aimed to explore if prenatal exposure to maternal obesity, smoking, and alcohol intake was associated with timing of puberty by use of a novel marker of pubertal timing: 'the height difference in standard deviations' (HD:SDS).

Methods: HD:SDS is the difference between pubertal height in standard deviations and adult height in standard deviations, and it correlates well with age at peak height velocity. Pubertal height was measured by health care professionals at approximately 13 years in boys and 11 years in girls, and the children's adult height was predicted from parental height reported by the mothers during pregnancy. Information on HD:SDS was available for 42,849 of 56,641 eligible boys and girls from the Danish National Birth Cohort born 2000-2003. In a subsample, HD:SDS was validated against age at the following self-reported pubertal milestones: Tanner stages, menarche, first ejaculation, voice break, acne, and axillary hair. Prenatal exposures were reported by mothers during pregnancy.

Results: HD:SDS correlated moderately with the pubertal milestones considered (correlation coefficients: -0.20 to - 0.53). With normal weight (body mass index (BMI): $18.5-24.9 \mathrm{~kg} / \mathrm{m}^{2}$ ) as the reference, maternal pre-pregnancy obesity (BMI: $30.0+\mathrm{kg} / \mathrm{m}^{2}$ ) was associated with earlier pubertal timing: 0.23 (95\% confidence interval (Cl): 0.18, 0.28) higher HD:SDS in boys and $0.19(95 \% \mathrm{Cl}, 0.14,0.24)$ higher HD:SDS in girls. Maternal smoking was not associated with pubertal timing. Compared to alcohol abstainers, maternal intake of $>3$ units of alcohol weekly was associated with later puberty in boys only: 0.14 (95\% Cl, 0.05, 0.24) lower HD:SDS.

Conclusion: As correlations between HD:SDS and the considered pubertal milestones were comparable to those reported in the literature between age a peak height velocity and the considered pubertal milestones, the validity of HD:SDS seems acceptable. Maternal pre-pregnancy obesity was associated with earlier pubertal timing in both sexes, and maternal alcohol intake during pregnancy was associated with later pubertal timing in boys. Maternal smoking has been linked to earlier timing of puberty, but this was not replicated in our setting using HD:SDS as a marker of pubertal timing.
\end{abstract}

Keywords: Puberty, Marker of pubertal timing, Prenatal exposures, Smoking, Alcohol consumption, Obesity, Age at menarche

\footnotetext{
* Correspondence: nis.brix@gmail.com

'Department of Public Health, Section for Epidemiology, Aarhus University, Bartholins Allé 2, 8000 Aarhus C, Denmark

${ }^{2}$ Department of Epidemiology, Fielding School of Public Health, University of

California Los Angeles (UCLA), Los Angeles, CA 90095-1772, USA

Full list of author information is available at the end of the article
}

(c) The Author(s). 2019 Open Access This article is distributed under the terms of the Creative Commons Attribution 4.0 International License (http://creativecommons.org/licenses/by/4.0/), which permits unrestricted use, distribution, and reproduction in any medium, provided you give appropriate credit to the original author(s) and the source, provide a link to the Creative Commons license, and indicate if changes were made. The Creative Commons Public Domain Dedication waiver (http://creativecommons.org/publicdomain/zero/1.0/) applies to the data made available in this article, unless otherwise stated. 


\section{Background}

During the last century, a trend toward earlier age at onset of puberty has been reported in girls, whereas the trend toward earlier age at menarche has leveled off in some countries since the 1960s [1, 2]. A trend is less clear in boys [2]. A change in timing of puberty over time is of concern because early pubertal timing has been associated with increased risk of adult diseases such as type 2 diabetes, cardiovascular diseases, testicular cancer, and breast cancer [3]. Identification of modifiable risk factors for earlier pubertal timing is, therefore, warranted. A potential modifiable risk factor for earlier pubertal timing is childhood obesity, which has been suggested to be responsible for some of the trend $[4,5]$. Prenatal exposures have also been suggested to interfere with pubertal timing through fetal growth restriction or overnutrition as well as endocrine disruption of androgenic or estrogenic activity [5, 6]. Maternal obesity, smoking, and alcohol intake during pregnancy may lead to either fetal growth restriction $[7,8]$ or overnutrition [9] and may change the intrauterine hormonal milieu towards either increased androgenic activity [10] or increased estrogenic activity [11, 12]. Hence, these maternal exposures may potentially interfere with pubertal timing in the children. In girls, earlier puberty has been observed after prenatal exposure to maternal obesity [13-19] and smoking [20-23]. No association for prenatal exposure to alcohol has been reported in girls in all [22, 24-26] but one small study [27]. In boys, some evidence support an earlier pubertal timing after prenatal exposure to smoking [23, 28-30], whereas results has been inconclusive for prenatal exposure to maternal obesity [31] and prenatal alcohol consumption $[26,32,33]$. If these associations reflect causal relations, they may open up for a potential for preventive actions as they are relatively frequent and modifiable [34-36].

Several markers of pubertal timing exist, but they all have limitations [2]: self-reported Tanner stages may be prone to misclassification, clinical assessment of Tanner stages may have high non-participation, age at peak height velocity (PHV) requires repeated height measures on each child, and hormonal analyses are expensive. Wehkalampi et al. developed a novel, low-cost, and simple marker of pubertal timing, namely 'the height difference in standard deviations' (HD:SDS) [37]. HD:SDS is the difference between pubertal height (measured around the mean age at PHV on the population level) in standard deviation scores (SDS) and adult height in SDS [37]. The rationale is that pubertal height is assumed to be mainly determined by the pubertal timing and the genetic growth potential, whereas adult height is assumed to be mainly determined by the genetic growth potential. By subtracting adult height SDS from pubertal height SDS, the genetic contribution of pubertal height is considered removed. The resulting HD:SDS is, in theory, only influenced by pubertal timing [37]. This is corroborated by empirical data revealing high correlation between HD:SDS and age at PHV [37].

We validated a modified version of HD:SDS. The modified HD:SDS relied on adult height predicted from parental height reported by the mothers during pregnancy because the children were not fully grown yet. Then, we explored how prenatal exposure to maternal obesity, smoking, and alcohol consumption were associated with timing of puberty, measured by HD:SDS, in boys and girls.

\section{Methods}

\section{Study population}

This population-based cohort study was based on the Danish National Birth Cohort (DNBC) [38]. The DNBC contains approximately 100,000 children and their mothers, who were recruited during early gestation in 1996-2002. Mothers were interviewed twice during pregnancy around week 17 and 32 of gestation, and their children were followed up at $0.5,1.5,7$ and 11 years of age. Mother-child pairs were eligible for the present study if the children were singletons born during 2000-2003, whose mothers had participated in the first computer-assisted telephone interview shortly after recruitment and had not withdrawn from the DNBC $(n=56,641)$ (Fig. 1$)$.

\section{Height difference in standard deviations (HD:SDS)}

The height SDS describes how far (in standard deviations) a person's actual height is from that person's expected height based on age and sex. As an example, if we plot a person's actual height on an age- and sex-specific growth chart, and this person's height lies on the curve 1 standard deviation below the mean curve, that person has a height SDS of -1 . HD:SDS is the estimated difference between pubertal height SDS and adult height SDS [37]. A child who matures early is expected to be younger at PHV, resulting in a higher pubertal height SDS, finally leading to a higher HD:SDS than a child who matures at an older age, whereas a child who matures late has a lower HD:SDS [37].

Pubertal height SDS was obtained from height measures in the Children's Database, a database initiated in 2009 aimed to systematically collect health related data on Danish children from school nurses and general practitioners [39]. Data for this study was extracted July 2017, and information on height was available on 51,751 of the 56,641 eligible children (91\%). Pubertal height should be measured around the mean age of PHV [37]. Hence, we chose to include the height measure at an age nearest to 13 years in boys and 11 years in girls (+/ -2 years) based on Danish growth curves from 2014 [40]. Children with no information on height within these sex-specific time ranges were excluded $(n=7858,14 \%)$. The height measures were converted to pubertal height SDS by use of the Danish growth curves [40], while excluding children with unreliable 


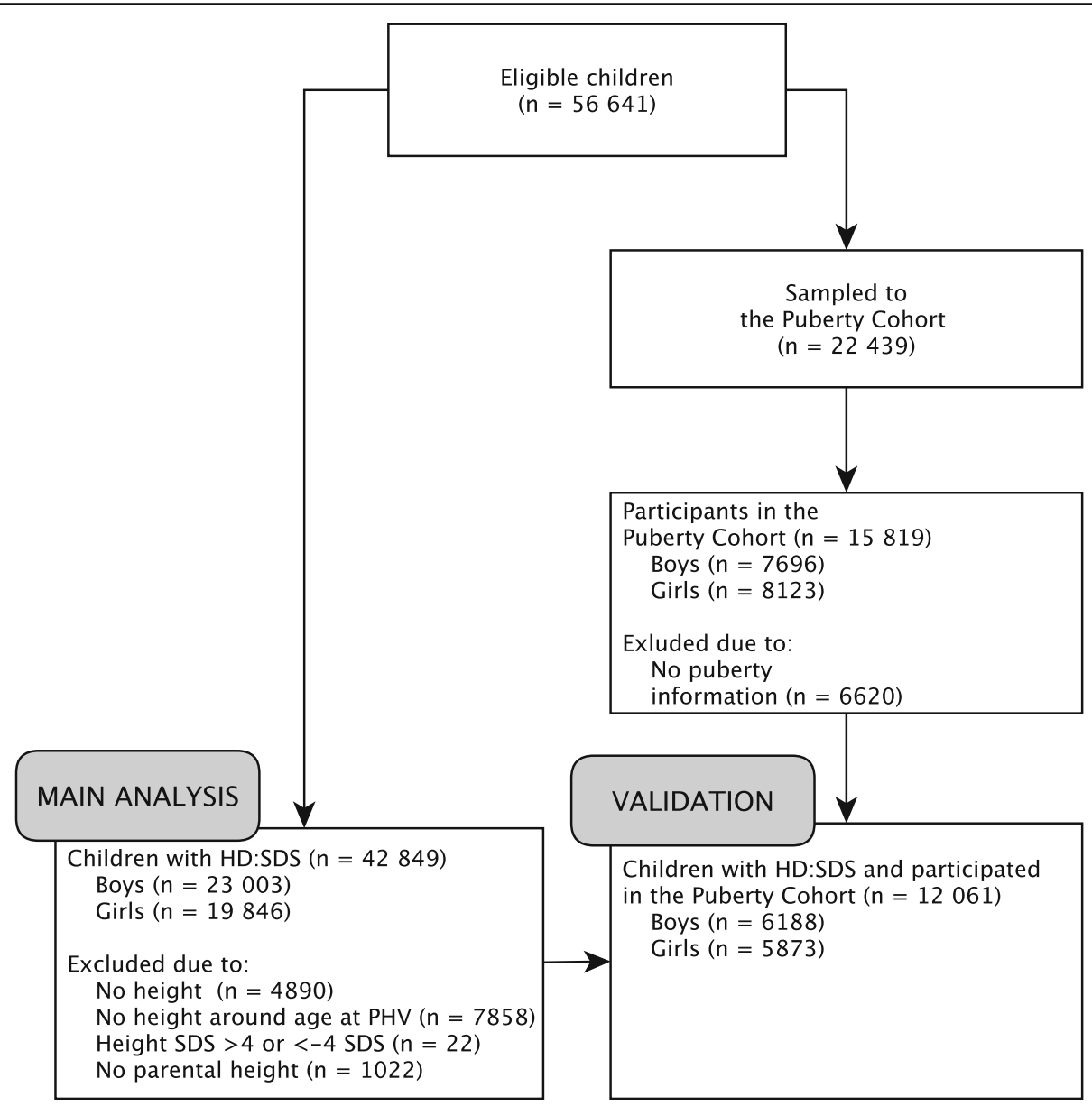

Fig. 1 Flow diagram of children in the main analysis and in the validation analysis of HD:SDS, the Danish National Birth Cohort, Denmark. Abbreviations: HD:SDS, height difference in standard deviations; PHV, peak height velocity; SDS, standard deviation score

pubertal height SDS $>4$ and $<-4 \quad(n=22)$. We were able to derive pubertal height SDS in 43,871 children (77\%).

As the children had not reached their final adult height yet, adult height SDS was estimated by the following two steps. First, we estimated adult height based on a prediction algorithm, developed in a large Swedish study [41] using information on maternal and paternal height from the DNBC's first interview during pregnancy. We excluded children with no information on maternal or paternal height $(n=1022)$. Second, we converted predicted adult height into adult height SDS using the Danish growth curves [40]. In total, we calculated HD:SDS for 23,003 boys and 19,846 girls with information on both pubertal and adult height SDS to obtain a final study sample of 42,849 children (76\%) (Fig. 1).

\section{Information on other pubertal milestones}

To estimate the validity of the modified HD:SDS, we used data on other pubertal milestones obtained from the Puberty Cohort, a nested cohort of 22,439 of the 56, 641 eligible children in the present study [23]. To ensure statistical power, the Puberty Cohort was sampled from 12 different prenatal exposures of interest, including the three investigated in the present study, and combined with a random sample $(n=8000)$ of all eligible children. Based on rules from probability theory, we calculated each child's probability of being sampled from the sampling fractions for each of the exposures and the random sample. The inverse of these probabilities were used as sampling weights to reweight the selected Puberty Cohort to represent a random sample of all 56,641 eligible children [23]. The Puberty Cohort was initiated in August 2012, and since then, 15,819 children (participation rate $70 \%$ ) have participated (Fig. 1). Participants provided information on their pubertal development at least once either as part of the larger 11-year follow-up in the DNBC or as part of the shorter half-yearly, puberty-specific questionnaires from the age of 11.5 years. Data for the present study were extracted in January 2018. In the questionnaires, sons self-reported information on their current Tanner stage for pubic hair and genital development (stage 1-5), first ejaculation (yes/ 
no; if yes: year and month), voice break (no/yes-sometimes/yes-definitive changes), acne (yes/no), and axillary hair (yes/no). Daughters self-reported information on Tanner stages for pubic hair and breast development (stage 1-5), menarche (yes/no; if yes: year and month), acne (yes/no), and axillary hair (yes/no). Information on Tanner stages was collected using the Sexual Maturation Scale, which includes line drawings of the five Tanner stages assisted by explanatory text [42-44].

\section{Prenatal exposures and covariates}

We considered maternal pre-pregnancy body mass index (BMI), maternal smoking in pregnancy, and maternal alcohol intake in pregnancy as prenatal exposures. From the first telephone interview in the DNBC, we extracted information on all three prenatal exposures, which were selfreported by the mothers around gestational week 17 . The covariate 'highest social class of parents' was classified according to the International Standard Class of Occupation and Education codes (ISCO-88 and ISCED) and obtained from Statistics Denmark. The covariates parity and maternal age at delivery were obtained from the Danish Medical Birth Registry, and the covariate maternal age at menarche was obtained from the first interview in the DNBC. Exposures and covariates were categorized as shown in Table 1. Childhood BMI was derived from height and weight reported by the mothers during the 7-year follow-up in the DNBC and was used in sub-analyses.

\section{Statistical analysis}

To estimate the validity of our modified HD:SDS as a marker of pubertal timing, we estimated the correlations between HD:SDS and age at attaining the pubertal milestones collected in the Puberty Cohort $(n=12,061)$ (Fig. 1). For comparison, we also estimated the correlations between age at first ejaculation and age at attaining the other pubertal milestones in boys and between age at menarche and age at attaining the other pubertal milestones in girls. We chose age at first ejaculation and menarche as we had more precise information on these variables. As the information on the pubertal milestones were collected half-yearly, these data were censored (either right, left, or interval censored), except for age at first ejaculation and age at menarche that were uncensored for some children because specific ages were provided by the children. To account for the censoring, we used a time-to-event approach to obtain the correlations by maximum likelihood estimation under the assumption of a bivariate normal distribution using STATA's -ml- package [45]. As the Puberty Cohort was sampled according to prenatal exposures of interest, we applied sampling weights, which have been described in detail previously [23].

In the main analysis, we used multivariable linear regression models for the three prenatal exposures to estimate difference in HD:SDS by exposure categories. To look for trends, we entered pre-pregnancy BMI $\left(\mathrm{kg} / \mathrm{m}^{2}\right)$, maternal smoking (categories as shown in Table 1), and alcohol consumption (units per week) as linear terms. Included potential confounders were highest social class of parents, parity, maternal age at delivery, maternal age at menarche, and the other exposures. Maternal age at delivery was included as a second order polynomial variable, while all other potential confounders was categorized as in Table 1 and included as indicator variables.

We conducted the following three sub-analyses. First, we assessed whether childhood BMI (continuous) modified the associations from the main analysis by including childhood BMI with interaction terms in each of the regression models as Houghton et al. found that postnatal growth patterns modified the association between maternal smoking and pubertal timing [46]. Second, we restricted the main analysis to having information on childhood BMI to assess possible bias due to missing information on childhood BMI (40\%). Then, we further adjusted the main analysis for childhood BMI to assess potential mediation by childhood BMI. Third, we expanded the sex-specific age range for eligible height data from $+/-2$ years to $+/-4$ years around the mean age at PHV to reduce the number of excluded children without height data within the age range from 7858 (14\%) to 1083 (2\%).

Robust standard errors were used to account for clustering of siblings $(n=1116)$ and the use of sampling weights. STATA 15.1 MP software (Statacorp, College Station, TX) was used for all analyses.

\section{Results}

\section{Study population}

Mean age (standard deviation) at height measures during puberty was $12.88(0.98)$ years in boys and $11.50(0.89)$ years in girls. Characteristics of the mother-child pairs are presented in Table 1.

When comparing mothers of children with information on HD:SDS to mothers of children without information on HD:SDS, maternal pre-pregnancy BMI, alcohol intake, maternal age at menarche, parity, and maternal age at delivery were similar (prevalence difference $<2 \%$ on any of these variables). Mothers of children with information on HD:SDS were slightly more likely to be non-smokers $(75.6 \%$ vs $71.9 \%)$ and to work as a high grade professional (24.0\% vs $21.9 \%)$ than mothers of children without information on HD:SDS. For the Puberty Cohort subsample, the only difference was a slightly higher proportion of mothers of children with information on HD:SDS were non-smokers $(75.4 \%$ vs $72.0 \%)$, whereas all other characteristics were equally distributed across children with and without information on HD:SDS.

\section{Validation of HD:SDS}

The correlation coefficients between HD:SDS and age at attaining the pubertal milestones ranged from -0.20 to 
Table 1 Background characteristics of mothers to children born 2000-2003, the Danish National Birth Cohort, Denmark

\begin{tabular}{|c|c|c|c|}
\hline Background Characteristics & $\begin{array}{l}\text { Boys }(n=23,003) \\
\text { No. }(\%)\end{array}$ & $\begin{array}{l}\text { Girls }(n=19,846) \\
\text { No. }(\%)\end{array}$ & $\begin{array}{l}\text { Missing } \\
\text { No. (\%) }\end{array}$ \\
\hline Pre-pregnancy BMI & & & $614(1.4)$ \\
\hline$<18.5 \mathrm{~kg} / \mathrm{m}^{2}$ & $984(4.3)$ & $833(4.3)$ & \\
\hline $18.5-24.9 \mathrm{~kg} / \mathrm{m}^{2}$ & $15,287(67.4)$ & $13,119(67.1)$ & \\
\hline $25.0-29.9 \mathrm{~kg} / \mathrm{m}^{2}$ & $4437(19.6)$ & $3875(19.8)$ & \\
\hline $30.0+\mathrm{kg} / \mathrm{m}^{2}$ & $1979(8.7)$ & $1721(8.8)$ & \\
\hline Smoking in pregnancy & & & $41(0.1)$ \\
\hline Non-smoker & $17,382(75.6)$ & $14,963(75.5)$ & \\
\hline Stopped smoking & $2194(9.5)$ & $1933(9.7)$ & \\
\hline 1-9 daily cigarettes & $1921(8.4)$ & $1667(8.4)$ & \\
\hline 10-14 daily cigarettes & $949(4.1)$ & $768(3.9)$ & \\
\hline $15+$ daily cigarettes & $532(2.3)$ & $499(2.5)$ & \\
\hline Alcohol in pregnancy & & & $16(0.0)$ \\
\hline Abstainer & $12,480(54.3)$ & $11,036(55.6)$ & \\
\hline$<1$ weekly units & $7199(31.3)$ & $6026(30.4)$ & \\
\hline $1-3$ weekly units & $2787(12.1)$ & $2362(11.9)$ & \\
\hline$>3$ weekly units & $527(2.3)$ & $416(2.1)$ & \\
\hline Maternal age of menarche & & & $373(0.9)$ \\
\hline Earlier than peers & $5638(24.7)$ & $5036(25.6)$ & \\
\hline Same time as peers & $13,359(58.6)$ & $11,278(57.4)$ & \\
\hline Later than peers & $3819(16.7)$ & $3346(17.0)$ & \\
\hline Highest social class of parents & & & $89(0.2)$ \\
\hline High grade professional & $5565(24.2)$ & $4718(23.8)$ & \\
\hline Low grade professional & $7271(31.7)$ & $6440(32.5)$ & \\
\hline Skilled worker & $6499(28.3)$ & $5552(28.0)$ & \\
\hline Unskilled worker & $3060(13.3)$ & $2620(13.2)$ & \\
\hline Student & $442(1.9)$ & $379(1.9)$ & \\
\hline Economically inactive & $115(0.5)$ & $99(0.5)$ & \\
\hline Parity & & & $1(0.0)$ \\
\hline First child & $11,146(48.5)$ & $9751(49.1)$ & \\
\hline Second child or more & $11,856(51.5)$ & $10,095(50.9)$ & \\
\hline Maternal age at delivery, years, mean (sd) & $30.5(4.2)$ & $30.4(4.2)$ & $23(0.1)$ \\
\hline Childhood BMI at 7 years, mean (sd) & $15.7(1.7)$ & $15.6(1.8)$ & $17,008(39.7)$ \\
\hline
\end{tabular}

BMI Body Mass Index, sd standard deviation

-0.53 for boys and from -0.30 to -0.53 for girls (Table 2). The correlations between age at first ejaculation and age at attaining the other pubertal milestones in boys ranged from 0.28 to 0.41 , and the correlations between age at menarche and age at attaining the other pubertal milestones in girls ranged from 0.37 to 0.71 .

\section{Prenatal exposures}

With normal weight (BMI: $18.5-24.9 \mathrm{~kg} / \mathrm{m}^{2}$ ) as the reference, maternal pre-pregnancy obesity (BMI: $30.0+$ $\mathrm{kg} / \mathrm{m}^{2}$ ) was associated with higher HD:SDS (boys: 0.23 (95\% confidence interval (CI): $0.18,0.28$ ); girls:
0.19 (95\% CI: 0.14, 0.24)) indicating earlier pubertal timing in both sexes (Table 3). Maternal prepregnancy overweight (BMI: $25.0-29.9 \mathrm{~kg} / \mathrm{m}^{2}$ ) was also associated with higher HD:SDS in both boys and girls. Dose-dependent associations were observed across BMI groups for both boys and girls. Maternal smoking in pregnancy was not associated with HD: SDS. Compared to maternal alcohol abstainers, intake of more than 3 weekly units of alcohol during pregnancy was associated with lower HD:SDS in boys only $(-0.14(95 \% \mathrm{CI},-0.24,-0.05))$ indicating delayed pubertal timing. 
Table 2 Correlations for HD:SDS, first ejaculation, and menarche with age at attaining other pubertal milestones in boys and girls born 2000-2003, the Puberty Cohort, Denmark

\begin{tabular}{|c|c|c|c|c|c|c|}
\hline \multirow[b]{2}{*}{ Pubertal milestones } & \multicolumn{3}{|c|}{ Correlations for HD:SDS } & \multicolumn{3}{|c|}{ Correlations for first ejaculation (boys) and menarche (girls } \\
\hline & $\overline{\text { No. }^{a}}$ & Estimate & $95 \% \mathrm{Cl}$ & No. & Estimate & $95 \% \mathrm{Cl}$ \\
\hline \multicolumn{7}{|l|}{ Boys } \\
\hline Tanner Genital Stage 2 & 6175 & -0.26 & $-0.29,-0.22$ & 7679 & 0.28 & $0.24,0.31$ \\
\hline Tanner Genital Stage 3 & 6175 & -0.39 & $-0.41,-0.36$ & 7679 & 0.36 & $0.32,0.39$ \\
\hline Tanner Genital Stage 4 & 6175 & -0.44 & $-0.46,-0.41$ & 7679 & 0.38 & $0.35,0.41$ \\
\hline Tanner Genital Stage 5 & 6175 & -0.32 & $-0.35,-0.28$ & 7679 & 0.28 & $0.24,0.31$ \\
\hline Tanner Pubic Hair Stage 2 & 6179 & -0.30 & $-0.33,-0.27$ & 7679 & 0.30 & $0.26,0.33$ \\
\hline Tanner Pubic Hair Stage 3 & 6179 & -0.45 & $-0.47,-0.42$ & 7679 & 0.37 & $0.34,0.40$ \\
\hline Tanner Pubic Hair Stage 4 & 6179 & -0.53 & $-0.56,-0.51$ & 7679 & 0.41 & $0.38,0.44$ \\
\hline Tanner Pubic Hair Stage 5 & 6179 & -0.44 & $-0.47,-0.41$ & 7679 & 0.37 & $0.34,0.41$ \\
\hline Axillary Hair & 6185 & -0.39 & $-0.42,-0.36$ & 7679 & 0.28 & $0.24,0.31$ \\
\hline Acne & 6185 & -0.31 & $-0.34,-0.28$ & 7679 & 0.28 & $0.24,0.31$ \\
\hline Voice Break & 6015 & -0.34 & $-0.37,-0.31$ & 7485 & 0.34 & $0.31,0.37$ \\
\hline First Ejaculation & 6171 & -0.20 & $-0.24,-0.17$ & & Ref & \\
\hline \multicolumn{7}{|l|}{ Girls } \\
\hline Tanner Breast Stage 2 & 5866 & -0.50 & $-0.54,-0.47$ & 8111 & 0.63 & $0.61,0.66$ \\
\hline Tanner Breast Stage 3 & 5866 & -0.53 & $-0.55,-0.50$ & 8111 & 0.71 & $0.69,0.72$ \\
\hline Tanner Breast Stage 4 & 5866 & -0.45 & $-0.48,-0.42$ & 8111 & 0.65 & $0.63,0.67$ \\
\hline Tanner Breast Stage 5 & 5866 & -0.33 & $-0.36,-0.29$ & 8111 & 0.46 & $0.43,0.48$ \\
\hline Tanner Pubic Hair Stage 2 & 5867 & -0.49 & $-0.52,-0.46$ & 8111 & 0.61 & $0.59,0.64$ \\
\hline Tanner Pubic Hair Stage 3 & 5867 & -0.48 & $-0.50,-0.45$ & 8111 & 0.64 & $0.62,0.66$ \\
\hline Tanner Pubic Hair Stage 4 & 5867 & -0.37 & $-0.40,-0.34$ & 8111 & 0.52 & $0.50,0.55$ \\
\hline Tanner Pubic Hair Stage 5 & 5867 & -0.30 & $-0.34,-0.27$ & 8111 & 0.40 & $0.37,0.43$ \\
\hline Axillary Hair & 5870 & -0.40 & $-0.43,-0.37$ & 8111 & 0.48 & $0.45,0.50$ \\
\hline Acne & 5870 & -0.30 & $-0.33,-0.27$ & 8111 & 0.37 & $0.34,0.40$ \\
\hline Menarche & 5864 & -0.53 & $-0.55,-0.51$ & & Ref & \\
\hline
\end{tabular}

Abbreviations: $\mathrm{Cl}$ Confidence interval, $H D$ :SDS Height difference in standard deviations, Ref Reference

${ }^{a}$ As some boys and girls gave information on some but not all pubertal milestones, different number of observations were used for each outcome

In sub-analyses, we found no statistically significant interaction between childhood BMI and maternal lifestyle exposures ( $P$-values ranged from 0.11 and 0.98$)$. When restricting to having information on childhood BMI, the results remained essentially unchanged (Model 1, Table 4). When further adjusting for childhood BMI, the associations for pre-pregnancy BMI were attenuated, the associations for maternal smoking in pregnancy shifted towards lower HD:SDS, and the associations for maternal alcohol intake in pregnancy remained unchanged (Model 2, Table 4). When expanding the sex-specific age range for eligible height data from $+/-2$ years to $+/-4$ years, the results for the main analysis remained essentially unchanged (Additional file 1: Table S1).

\section{Discussions}

HD:SDS was moderately correlated with age at attaining other pubertal milestones. When using HD:SDS as a marker of pubertal timing, higher maternal pre-pregnancy BMI was associated with earlier pubertal timing in both boys and girls. Maternal alcohol consumption during pregnancy was associated with later pubertal timing in boys only, whereas maternal smoking was not associated with pubertal timing using HD:SDS. We found no evidence of interaction between childhood BMI and the three prenatal exposures. Childhood BMI seemed to mediate the association between pre-pregnancy BMI and HD:SDS.

\section{Interpretation}

Both HD:SDS and age at PHV capture the timing of accelerated linear growth in puberty. This is supported by strong correlations between HD:SDS and age at PHV of 0.84 in boys and 0.78 in girls [37]. However, age at PHV has large variability across Tanner stages [47], and lower correlations for both HD:SDS and PHV with the other pubertal milestones are expected. This is supported by a 
Table 3 Prenatal exposures and pubertal timing, measured by HD:SDS ${ }^{\mathrm{a}}$, in children born 2000-2003, the Danish National Birth Cohort, Denmark

\begin{tabular}{|c|c|c|c|c|c|c|}
\hline \multirow[b]{3}{*}{ Prenatal exposures } & \multicolumn{3}{|c|}{ Boys $(n=22,409)$} & \multicolumn{3}{|c|}{ Girls $(n=19,301)$} \\
\hline & \multirow{2}{*}{$\begin{array}{l}\text { Crude } \\
\text { Difference }\end{array}$} & \multicolumn{2}{|l|}{ Adjusted $^{b}$} & \multirow{2}{*}{$\begin{array}{l}\text { Crude } \\
\text { Difference }\end{array}$} & \multicolumn{2}{|l|}{ Adjusted $^{\mathrm{b}}$} \\
\hline & & Difference & $95 \% \mathrm{Cl}$ & & Difference & $95 \% \mathrm{Cl}$ \\
\hline \multicolumn{7}{|l|}{ Pre-pregnancy BMI } \\
\hline$<18.5 \mathrm{~kg} / \mathrm{m}^{2}$ & -0.15 & -0.13 & $-0.19,-0.06$ & -0.10 & -0.07 & $-0.14,-0.01$ \\
\hline $18.5-24.9 \mathrm{~kg} / \mathrm{m}^{2}$ & Ref & Ref & & Ref & Ref & \\
\hline $25.0-29.9 \mathrm{~kg} / \mathrm{m}^{2}$ & 0.17 & 0.12 & $0.09,0.16$ & 0.15 & 0.10 & $0.06,0.13$ \\
\hline $30.0+\mathrm{kg} / \mathrm{m}^{2}$ & 0.30 & 0.23 & $0.18,0.28$ & 0.26 & 0.19 & $0.14,0.24$ \\
\hline Trend analysis $\left(\mathrm{kg} / \mathrm{m}^{2}\right)$ & 0.027 & 0.021 & $0.018,0.024$ & 0.025 & 0.019 & $0.015,0.022$ \\
\hline \multicolumn{7}{|l|}{ Smoking in pregnancy } \\
\hline Non-smoker & Ref & Ref & & Ref & Ref & \\
\hline Stopped smoking & -0.01 & -0.01 & $-0.05,0.04$ & -0.03 & -0.04 & $-0.08,0.01$ \\
\hline 1-9 daily cigarettes & -0.01 & -0.02 & $-0.07,0.03$ & 0.05 & 0.03 & $-0.02,0.08$ \\
\hline 10-14 daily cigarettes & 0.05 & 0.01 & $-0.06,0.08$ & 0.09 & 0.04 & $-0.03,0.11$ \\
\hline $15+$ daily cigarettes & 0.03 & -0.02 & $-0.11,0.07$ & 0.11 & 0.02 & $-0.07,0.11$ \\
\hline Trend analysis (group) & 0.007 & -0.003 & $-0.017,0.011$ & 0.023 & 0.008 & $-0.007,0.022$ \\
\hline \multicolumn{7}{|l|}{ Alcohol in pregnancy } \\
\hline Abstainers & Ref & Ref & & Ref & Ref & \\
\hline$<1$ units weekly & -0.01 & 0.00 & $-0.03,0.03$ & -0.03 & -0.02 & $-0.05,0.01$ \\
\hline 1-3 units weekly & -0.05 & -0.02 & $-0.07,0.02$ & -0.05 & -0.02 & $-0.07,0.02$ \\
\hline$>3$ units weekly & -0.16 & -0.14 & $-0.24,-0.05$ & -0.01 & 0.00 & $-0.10,0.09$ \\
\hline Trend analysis (units) & -0.027 & -0.021 & $-0.035,-0.008$ & -0.013 & -0.006 & $-0.019,0.007$ \\
\hline
\end{tabular}

Abbreviations: BMI Body Mass Index, Cl Confidence interval, Ref Reference, HD:SDS Height difference in standard deviations

${ }^{a} A$ negative HD:SDS indicates later pubertal timing, and a positive HD:SDS indicates earlier pubertal timing

${ }^{\mathrm{b}}$ Adjusted for highest social class of parents, parity, maternal age at delivery, maternal age at menarche and all other exposures (in categories) in this table

recent study that reported correlations of 0.27 between age at PHV and onset of breast development and 0.48 between age at PHV and menarche [48]. This is comparable to the correlations around -0.30 to -0.50 for HD: SDS and age at attaining the majority of the pubertal milestones in the present study. In comparison, the correlations between age at first ejaculation and the other pubertal milestones in boys were in the same range, although the correlations between age at menarche and the other pubertal milestones in girls were slightly higher. As the correlations between HD:SDS and age at attaining the pubertal milestones were within the expected ranged, the validity of our modified version of HD:SDS as a marker of pubertal timing seems acceptable in large epidemiological studies.

We found that exposure to maternal pre-pregnancy obesity and overweight was associated with higher HD: SDS indicating earlier pubertal timing in both boys and girls. These associations have been well-documented in girls [13-19]. In comparison, the only study so far in boys reported earlier age at regular shavings but no difference in age at voice break, first nocturnal ejaculation, and acne in sons of obese mothers [31]. That study was, however, limited by self-reported information on puberty when the boys were 18 to 21 years old [31]. Obese mothers are at increased risk of having obese children $[9,49]$, which, in turn, is associated with earlier puberty [4]. Hence, childhood obesity may play a mediatory role for the observed associations. When we adjusted for childhood BMI in the present study, the results attenuated supporting a mediatory role of child BMI in line with some $[15,16,19]$ but not all studies $[13,14]$ in girls.

In a recent study from the Puberty Cohort, maternal smoking during pregnancy was consistently associated with earlier age at reaching a wide range of pubertal markers in both boys and girls [23]. Maternal smoking was, however, not associated with pubertal timing when measured by HD:SDS. We speculate that this null finding may be induced by the following biasing mechanism. Prenatal smoking has been associated with impaired growth throughout life [50] and may, therefore, result in lower pubertal height SDS and lower adult height SDS. When predicting adult height SDS from parental height, we, therefore, could be overestimating adult height SDS in children of smoking mothers because the prediction algorithm does not account for the shorter final adult 
Table 4 Prenatal exposures and pubertal timing, measured by HD:SDS${ }^{\mathrm{a}}$, when further adjusting for childhood BMI at 7 years in children born 2000-2003, the Danish National Birth Cohort, Denmark

\begin{tabular}{|c|c|c|c|c|}
\hline \multirow[b]{2}{*}{ Prenatal exposures } & \multicolumn{2}{|c|}{$\begin{array}{l}\text { Model } 1^{\mathrm{b}} \text { : Adjusted difference in HD:SDS } \\
\text { when restricting to information on } \\
\text { childhood BMl }\end{array}$} & \multicolumn{2}{|c|}{$\begin{array}{l}\text { Model } 2^{c} \text { : Adjusted difference in HD:SDS } \\
\text { when also adjusting for childhood BMI }\end{array}$} \\
\hline & Difference & $95 \% \mathrm{Cl}$ & Difference & $95 \% \mathrm{Cl}$ \\
\hline \multicolumn{5}{|l|}{ Boys $(n=13,674)$} \\
\hline \multicolumn{5}{|l|}{ Pre-pregnancy BMI } \\
\hline$<18.5 \mathrm{~kg} / \mathrm{m}^{2}$ & -0.17 & $-0.26,-0.08$ & -0.12 & $-0.20,-0.03$ \\
\hline $18.5-24.9 \mathrm{~kg} / \mathrm{m}^{2}$ & Ref & & Ref & \\
\hline $25.0-29.9 \mathrm{~kg} / \mathrm{m}^{2}$ & 0.12 & $0.07,0.16$ & 0.06 & $0.01,0.10$ \\
\hline $30.0+\mathrm{kg} / \mathrm{m}^{2}$ & 0.24 & $0.18,0.31$ & 0.13 & $0.06,0.19$ \\
\hline Trend analysis $\left(\mathrm{kg} / \mathrm{m}^{2}\right)$ & 0.023 & $0.018,0.027$ & 0.012 & $0.007,0.016$ \\
\hline \multicolumn{5}{|l|}{ Smoking in pregnancy } \\
\hline Non-smoker & Ref & & Ref & \\
\hline Stopped smoking & 0.00 & $-0.05,0.06$ & -0.02 & $-0.07,0.04$ \\
\hline 1-9 daily cigarettes & -0.01 & $-0.07,0.06$ & -0.05 & $-0.12,0.01$ \\
\hline 10-14 daily cigarettes & 0.01 & $-0.09,0.11$ & -0.04 & $-0.13,0.06$ \\
\hline $15+$ daily cigarettes & 0.01 & $-0.13,0.14$ & -0.05 & $-0.18,0.08$ \\
\hline Trend analysis (group) & 0.001 & $-0.018,0.021$ & -0.016 & $-0.036,0.003$ \\
\hline \multicolumn{5}{|l|}{ Alcohol in pregnancy } \\
\hline Abstainers & Ref & & Ref & \\
\hline$<1$ units weekly & 0.00 & $-0.04,0.04$ & 0.00 & $-0.04,0.04$ \\
\hline 1-3 units weekly & 0.00 & $-0.06,0.05$ & 0.00 & $-0.05,0.05$ \\
\hline$>3$ units weekly & -0.12 & $-0.23,-0.01$ & -0.11 & $-0.22,0.00$ \\
\hline Trend analysis (units) & -0.018 & $-0.035,-0.002$ & -0.017 & $-0.033,0.000$ \\
\hline \multicolumn{5}{|l|}{ Girls $(n=11,550)$} \\
\hline \multicolumn{5}{|l|}{ Pre-pregnancy BMI } \\
\hline$<18.5 \mathrm{~kg} / \mathrm{m}^{2}$ & -0.02 & $-0.11,0.07$ & 0.05 & $-0.04,0.14$ \\
\hline $18.5-24.9 \mathrm{~kg} / \mathrm{m}^{2}$ & Ref & & Ref & \\
\hline $25.0-29.9 \mathrm{~kg} / \mathrm{m}^{2}$ & 0.10 & $0.06,0.15$ & 0.04 & $-0.01,0.08$ \\
\hline $30.0+\mathrm{kg} / \mathrm{m}^{2}$ & 0.16 & $0.09,0.24$ & 0.05 & $-0.02,0.11$ \\
\hline Trend analysis $\left(\mathrm{kg} / \mathrm{m}^{2}\right)$ & 0.018 & $0.014,0.023$ & 0.007 & $0.002,0.011$ \\
\hline \multicolumn{5}{|l|}{ Smoking in pregnancy } \\
\hline Non-smoker & Ref & & Ref & \\
\hline Stopped smoking & -0.05 & $-0.11,0.00$ & -0.08 & $-0.14,-0.02$ \\
\hline 1-9 daily cigarettes & 0.03 & $-0.04,0.10$ & -0.03 & $-0.09,0.04$ \\
\hline 10-14 daily cigarettes & 0.05 & $-0.06,0.15$ & 0.00 & $-0.10,0.10$ \\
\hline $15+$ daily cigarettes & 0.04 & $-0.10,0.19$ & -0.02 & $-0.16,0.12$ \\
\hline Trend analysis (group) & 0.009 & $-0.012,0.029$ & -0.012 & $-0.032,0.008$ \\
\hline \multicolumn{5}{|l|}{ Alcohol in pregnancy } \\
\hline Abstainers & & & Ref & \\
\hline$<1$ units weekly & -0.03 & $-0.07,0.01$ & -0.03 & $-0.07,0.01$ \\
\hline $1-3$ units weekly & -0.06 & $-0.11,0.00$ & -0.06 & $-0.12,-0.01$ \\
\hline$>3$ units weekly & 0.02 & $-0.11,0.14$ & 0.00 & $-0.12,0.12$ \\
\hline Trend analysis (units) & -0.012 & $-0.029,0.006$ & -0.014 & $-0.031,0.003$ \\
\hline
\end{tabular}

Abbreviations: BMI Body Mass Index, Cl Confidence interval, Ref Reference, $H D$ :SDS Height difference in standard deviations

${ }^{\mathrm{a}} \mathrm{A}$ negative HD:SDS indicates later pubertal timing, and a positive HD:SDS indicates earlier pubertal timing

${ }^{\mathrm{b}}$ Model 1 is restricted to having information on childhood BMI and adjusted for highest social class of parents, parity, maternal age at delivery, maternal age at menarche and all other exposures (in categories) in this table

'Model 2 is adjusted for childhood BMI, highest social class of parents, parity, maternal age at delivery, maternal age at menarche and all other exposures (in categories) in this table 
height due maternal smoking in pregnancy. This might lead to a downward bias of HD:SDS among children of smoking mothers that could potentially cancel out the expected association with maternal smoking [23]. In a sub-analysis, we also adjusted for childhood BMI, and the associations for maternal smoking shifted towards lower HD:SDS, although with more uncertainty. This finding warrants a cautious interpretation due to the possible bias described above.

For boys prenatally exposed to maternal alcohol, we observed a smaller HD:SDS, indicating later pubertal timing. Moreover, the association remained unchanged after adjustment for childhood BMI, indicating that other pathways may be at play. So far, studies on maternal alcohol intake during pregnancy have found no association with pubertal timing in boys when using average weekly intake as the exposure [26, 32, 33]. One of these studies, however, reported a tendency towards later pubertal timing when prenatally exposed to $\geq 5$ episodes of binge drinking [33]. A potential delaying effect on pubertal timing by prenatal alcohol is supported by animal studies that have reported smaller testes, lower postnatal androgens, shorter anogenital distance, and delayed markers of pubertal timing in male rats prenatally exposed to alcohol [51-53]. Likewise, prenatal alcohol seems to delay pubertal timing in female mice and rats [53-55]. However, most epidemiologic studies on pubertal timing in girls after moderate prenatal alcohol exposure have found no association, which is in line with our results [22, 24-26]. The reason for this discrepancy between sexes might be that boys are more prone to morbidity as neonates than girls. Although speculative, this might explain that we only observe an association for boys at the exposure level in our study. In line with this, girls exposed to high maternal alcohol intake ( $\geq 14$ units per week) were found to experience later menarche in one study, although that study was small with no adjustment for confounders [27]. Thus, we cannot exclude a delaying effect of prenatal exposure to higher levels of alcohol in girls.

Over the last decades, trends towards reduced alcohol intake during pregnancy $[35,56,57]$ and increased prevalence of obesity have been observed [36]. Whereas the association between prenatal exposure to alcohol and pubertal timing in boys needs to be replicated, increased prevalence of obesity during pregnancy might explain some of the trend in pubertal timing.

\section{Strengths and limitations}

The main strengths of the present study were its large size, the use of pubertal height data measured by health care professionals, and the validation of HD:SDS using information on other pubertal milestone from a puberty cohort. An important limitation was that the children were not fully grown, and we, therefore, had to rely on predictions based on parental height, which lead to some measurement error. This is especially important if the exposures affect postnatal growth. If so, the prediction algorithm for adult height may systematically overestimate or underestimate adult height among the exposed leading to biased estimates. This is possibly the case for maternal smoking as discussed above. As obese children generally achieve normal adult height [4], we speculate that children exposed in utero to maternal prepregnancy obesity will most likely also achieve normal adult height. Similarly, the relatively low exposure level to prenatal alcohol in the present study will probably not interfere with growth in the children, although heavy prenatal alcohol exposure may lead to growth restriction, a feature of Fetal Alcohol Syndrome [8]. Hence, the estimates for maternal pre-pregnancy BMI and alcohol intake need not be systematically biased. Under more restricted conditions such as poverty or famine, HD:SDS might break down as a marker of pubertal timing because the children might not reach their full genetic growth potential during childhood, puberty, and adulthood. Due to the observational nature of this study, we cannot rule out that residual confounding or confounding from unmeasured factors, such as diet or genetic factors, have influenced the results. Even though we had information on HD:SDS for $76 \%$ of the participants, we cannot rule out the risk of selection bias. However, the background characteristics were relatively evenly distributed across children with and without information on HD:SDS. Including further $12 \%$ more children in the main analysis (participation rate $89 \%$ ), by expanding the sex-specific age range for having eligible height data, did not change the results. The relatively late start of followup at 11 years resulted in a relatively large proportion of left-censored observations for the earliest milestones, which may bias the correlations between HD:SDS and the age at attaining the earliest pubertal milestones if the assumption of the bivariate normal distribution is violated. For the earliest milestones, such as Tanner Breast stage 2, it is not possible to assess the assumption of normality as we do not have information on the left $85 \%$ of the distribution. However, all later milestones were compatible with the normal distribution [58].

\section{Conclusions}

HD:SDS appears to be a useful marker of pubertal timing in large epidemiological studies. Maternal pre-pregnancy obesity and overweight were associated with earlier timing of puberty in both boys and girls, while maternal alcohol intake in pregnancy was associated with delayed puberty in boys. When relying on predicted adult height SDS from parental data, a cautious interpretation is needed for prenatal exposures that interfere with postnatal growth. This 
may explain why the present study did not replicate the previously reported association between maternal smoking and early pubertal timing.

\section{Supplementary information}

Supplementary information accompanies this paper at https://doi.org/10. 1186/s12887-019-1715-0

Additional file 1: Table S1. Sub-analysis: Prenatal exposures and pubertal timing, measured by HD:SDS ${ }^{\mathrm{a}}$, when including children with height data $+/-4$ years around the man age at peak height velocity in children born 2000-2003, the Danish National Birth Cohort, Denmark.

\section{Abbreviations}

BMI: Body mass index; Cl: Confidence interval; DNBC: Danish National Birth Cohort; HD:SDS: Height difference in standard deviations; PHV: Peak height velocity; SDS: Standard deviation scores

\section{Acknowledgements}

None.

\begin{abstract}
Authors' contributions
$\mathrm{NB}, \mathrm{JO}$ and $\mathrm{CHRH}$ conceptualized and designed the study. JO and $\mathrm{CHRH}$ were responsible for acquisition of data. NB analyzed the data. NB, $A E, L L B L$, ETP, OAA, JO, TBH and $\mathrm{CHRH}$ interpreted the results. NB made the initial draft. NB, AE, LLBL, ETP, OAA, JO, TBH and CHRH revised the paper critically for important intellectual content, approved the final version to be published and agrees to be accountable for all aspects of the work in ensuring that questions related to the accuracy or integrity of any part of the work are appropriately investigated and resolved.
\end{abstract}

\section{Funding}

This study was funded by the Danish Council for Independent Research (DFF - 4183-00152), Aarhus University, Jorck's Foundation, the Denmark-America Foundation, and the Oticon Foundation. The funders had no role in the design of the study and collection, analysis, and interpretation of data and in writing the manuscript.

The Danish National Birth Cohort was established with a significant grant from the Danish National Research Foundation. Additional support was obtained from the Danish Regional Committees, the Pharmacy Foundation, the Egmont Foundation, the March of Dimes Birth Defects Foundation, the Health Foundation and other minor grants. The DNBC Biobank has been supported by the Novo Nordisk Foundation and the Lundbeck Foundation. Follow-up of mothers and children have been supported by the Danish Medical Research Council (SSVF 0646, 271-08-0839/06-066023, O602-01042B, 0602-02738B), the Lundbeck Foundation (195/04, R100-A9193), The Innovation Fund Denmark 0603-00294B (09-067124), the Nordea Foundation (02-2013-2014), Aarhus Ideas (AU R9-A959-13-S804), University of Copenhagen Strategic Grant (IFSV 2012), and the Danish Council for Independent Research (DFF - 4183-00594 and DFF - 4183-00152).

\section{Availability of data and materials}

The dataset analyzed in the study is not publicly available due to national data security legislation on sensitive personal data. Access to data can be applied for at dnbc-research@ssi.dk.

\section{Ethics approval and consent to participate}

The Committee for Biomedical Research Ethics in Denmark approved the prospective collection of data in the DNBC ((KF)01-471/94). A written informed consent was obtained from mothers upon recruitment covering both mother's and offspring's participation until they turn 18 years of age. Data on the children's height were based on existing data from a national registry, the Children's Database. The present study was registered at The Danish Data Protection Agency (2015-57-0002)

\section{Consent for publication}

Not applicable.

\section{Competing interests}

The authors declare that they have no competing interests.

\section{Author details}

${ }^{1}$ Department of Public Health, Section for Epidemiology, Aarhus University, Bartholins Allé 2, 8000 Aarhus C, Denmark. ²Department of Epidemiology, Fielding School of Public Health, University of California Los Angeles (UCLA), Los Angeles, CA 90095-1772, USA. ³ Department of Public Health, Section for Biostatistics, Aarhus University, DK-8000 Aarhus, Denmark. ${ }^{4}$ Department of Statistics, UCLA College of Letters and Science, Los Angeles, CA 90095-1554, USA. ${ }^{5}$ Department of Clinical Epidemiology, Aarhus University Hospital, DK-8200 Aarhus, Denmark. ${ }^{6}$ Perinatal Epidemiology Research Unit, Department of Paediatrics, Aarhus University Hospital, DK-8200 Aarhus, Denmark.

Received: 13 November 2018 Accepted: 9 September 2019

Published online: 16 September 2019

\section{References}

1. Ong KK, Ahmed ML, Dunger DB. Lessons from large population studies on timing and tempo of puberty (secular trends and relation to body size): the European trend. Mol Cell Endocrinol. 2006;254-255:8-12.

2. Euling SY, Herman-Giddens ME, Lee PA, Selevan SG, Juul A, Sorensen TI, et al. Examination of US puberty-timing data from 1940 to 1994 for secular trends: panel findings. Pediatrics. 2008;121(Suppl 3):S172-91.

3. Golub MS, Collman GW, Foster PM, Kimmel CA, Rajpert-De Meyts E, Reiter EO, et al. Public health implications of altered puberty timing. Pediatrics. 2008;121(Suppl 3):S218-30.

4. Wagner IV, Sabin MA, Pfaffle RW, Hiemisch A, Sergeyev E, Korner A, et al. Effects of obesity on human sexual development. Nat Rev Endocrinol. 2012:8:246-54.

5. Lee $Y$, Styne D. Influences on the onset and tempo of puberty in human beings and implications for adolescent psychological development. Horm Behav. 2013:64:250-61.

6. Roth $\mathrm{CL}$, DiVall S. Consequences of early life programing by genetic and environmental influences: a synthesis regarding pubertal timing. Endocr Dev. 2016;29:134-52

7. Pereira PP, Da Mata FA, Figueiredo AC, de Andrade KR, Pereira MG. Maternal active smoking during pregnancy and low birth weight in the Americas: a systematic review and meta-analysis. Nicotine Tob Res. 2017;19:497-505.

8. Jones KL, Smith DW. Recognition of the fetal alcohol syndrome in early infancy. Lancet. 1973;302:999-1001.

9. Yu Z, Han S, Zhu J, Sun X, Ji C, Guo X. Pre-pregnancy body mass index in relation to infant birth weight and offspring overweight/obesity: a systematic review and meta-analysis. PLoS One. 2013;8:e61627.

10. Toriola AT, Vaarasmaki M, Lehtinen M, Zeleniuch-Jacquotte A, Lundin E, Rodgers $\mathrm{KG}$, et al. Determinants of maternal sex steroids during the first half of pregnancy. Obstet Gynecol. 2011;118:1029-36.

11. Pettigrew R, Hamilton-Fairley D. Obesity and female reproductive function Br Med Bull. 1997:53:341-58.

12. Nagata C, Iwasa S, Shiraki M, Sahashi Y, Shimizu H. Association of maternal fat and alcohol intake with maternal and umbilical hormone levels and birth weight. Cancer Sci. 2007;98:869-73.

13. Deardorff J, Berry-Millett R, Rehkopf D, Luecke E, Lahiff M, Abrams B. Maternal pre-pregnancy BMI, gestational weight gain, and age at menarche in daughters. Matern Child Health J. 2013;17:1391-8.

14. Keim SA, Branum AM, Klebanoff MA, Zemel BS. Maternal body mass index and daughters' age at menarche. Epidemiology. 2009;20:677-81.

15. Shrestha A, Olsen J, Ramlau-Hansen $\mathrm{CH}$, Bech BH, Nohr EA. Obesity and age at menarche. Fertil Steril. 2011:95:2732-4.

16. Lawn RB, Lawlor DA, Fraser A. Associations between maternal prepregnancy body mass index and gestational weight gain and daughter's age at menarche: the avon longitudinal study of parents and children. Am J Epidemiol. 2018;187:677-86.

17. Mariansdatter SE, Ernst A, Toft G, Olsen SF, Vested A, Kristensen SL, et al. Maternal pre-pregnancy BMI and reproductive health of daughters in young adulthood. Matern Child Health J. 2016:20:2150-9.

18. Windham GC, Zhang L, Longnecker MP, Klebanoff M. Maternal smoking, demographic and lifestyle factors in relation to daughter's age at menarche. Paediatr Perinat Epidemiol. 2008;22:551-61.

19. Kubo A, Deardorff J, Laurent CA, Ferrara A, Greenspan LC, Quesenberry CP, et al. Associations between maternal obesity and pregnancy hyperglycemia 
and timing of puberty onset in adolescent girls: a population-based study. Am J Epidemiol. 2018;187:1362-9.

20. Yermachenko A, Dvornyk V. A meta-analysis provides evidence that prenatal smoking exposure decreases age at menarche. Reprod Toxicol. 2015;58:222-8.

21. Windham GC, Lum R, Voss R, Wolff M, Pinney SM, Teteilbaum SL, et al. Age at pubertal onset in girls and tobacco smoke exposure during pre- and postnatal susceptibility windows. Epidemiology. 2017;28:719-27.

22. Maisonet M, Christensen KY, Rubin C, Holmes A, Flanders WD, Heron J, et al. Role of prenatal characteristics and early growth on pubertal attainment of British girls. Pediatrics. 2010;126:e591-600.

23. Brix N, Ernst A, Lauridsen LLB, Parner ET, Olsen J, Henriksen TB, et al. Maternal smoking during pregnancy and timing of puberty in sons and daughters: a population-based cohort study. Am J Epidemiol. 2019;188:47-56.

24. Windham GC, Bottomley C, Birner C, Fenster L. Age at menarche in relation to maternal use of tobacco, alcohol, coffee, and tea during pregnancy. Am J Epidemiol. 2004;159:862-71.

25. Shrestha A, Nohr EA, Bech BH, Ramlau-Hansen CH, Olsen J. Smoking and alcohol use during pregnancy and age of menarche in daughters. Hum Reprod. 2011;26:259-65.

26. Carter RC, Jacobson JL, Dodge NC, Granger DA, Jacobson SW. Effects of prenatal alcohol exposure on testosterone and pubertal development. Alcohol Clin Exp Res. 2014;38:1671-9.

27. Robe $L B$, Robe RS, Wilson PA. Maternal heavy drinking related to delayed onset of daughters menstruation. Curr Alcohol. 1979;7:515-20

28. Fried PA, James DS, Watkinson B. Growth and pubertal milestones during adolescence in offspring prenatally exposed to cigarettes and marihuana. Neurotoxicol Teratol. 2001;23:431-6.

29. Hakonsen LB, Olsen J, Stovring H, Ernst A, Thulstrup AM, Zhu JL, et al. Maternal cigarette smoking during pregnancy and pubertal development in sons. A follow-up study of a birth cohort. Andrology. 2013;1:348-55.

30. Ravnborg TL, Jensen TK, Andersson AM, Toppari J, Skakkebaek NE, Jorgensen N. Prenatal and adult exposures to smoking are associated with adverse effects on reproductive hormones, semen quality, final height and body mass index. Hum Reprod. 2011;26:1000-11.

31. Hounsgaard ML, Hakonsen LB, Vested A, Thulstrup AM, Olsen J, Bonde JP, et al. Maternal pre-pregnancy body mass index and pubertal development among sons. Andrology. 2014;2:198-204.

32. Monteilh C, Kieszak S, Flanders WD, Maisonet M, Rubin C, Holmes AK, et al. Timing of maturation and predictors of Tanner stage transitions in boys enrolled in a contemporary British cohort. Paediatr Perinat Epidemiol. 2011;25:75-87.

33. Hakonsen LB, Brath-Lund ML, Hounsgaard ML, Olsen J, Ernst A, Thulstrup $\mathrm{AM}$, et al. In utero exposure to alcohol and puberty in boys: a pregnancy cohort study. BMJ Open. 2014;4:e004467.

34. Cnattingius $\mathrm{S}$. The epidemiology of smoking during pregnancy: smoking prevalence, maternal characteristics, and pregnancy outcomes. Nicotine Tob Res. 2004;6(Suppl 2):S125-40.

35. Kesmodel US, Petersen GL, Henriksen TB, Strandberg-Larsen K. Time trends in alcohol intake in early pregnancy and official recommendations in Denmark, 1998-2013. Acta Obstet Gynecol Scand. 2016;95:803-10.

36. Ogden CL, Yanovski SZ, Carroll MD, Flegal KM. The epidemiology of obesity. Gastroenterology. 2007;132:2087-102.

37. Wehkalampi K, Silventoinen K, Kaprio J, Dick DM, Rose RJ, Pulkkinen L, et al. Genetic and environmental influences on pubertal timing assessed by height growth. Am J Hum Biol. 2008;20:417-23.

38. Olsen J, Melbye M, Olsen SF, Sorensen TI, Aaby P, Andersen AM, et al. The Danish National Birth Cohort--its background, structure and aim. Scand J Public Health. 2001;29:300-7.

39. Høghsbro C: http://www.esundhed.dk/dokumentation/Registre/Sider/ Register.aspx?rp:A_Register=20\&rp:Visning=0\&. Accessed 25 Oct 2018.

40. Tinggaard J, Aksglaede L, Sorensen K, Mouritsen A, Wohlfahrt-Veje C, Hagen $C P$, et al. The 2014 Danish references from birth to 20 years for height, weight and body mass index. Acta Paediatr. 2014;103:214-24.

41. Luo ZC, Albertsson-Wikland K, Karlberg J. Target height as predicted by parental heights in a population-based study. Pediatr Res. 1998;44:563-71.

42. Marshall WA, Tanner JM. Variations in pattern of pubertal changes in girls. Arch Dis Child. 1969:44:291-303.

43. Marshall WA, Tanner JM. Variations in the pattern of pubertal changes in boys. Arch Dis Child. 1970;45:13-23.

44. Morris NM, Udry JR. Validation of a self-administered instrument to assess stage of adolescent development. J Youth Adolesc. 1980;9:271-80.
45. Sun J. The statistical analysis of interval-censored failure time data. New York: Springer; 2006.

46. Houghton LC, Goldberg M, Wei Y, Cirillo PM, Cohn BA, Michels KB, et al. Why do studies show different associations between intrauterine exposure to maternal smoking and age at menarche? Ann Epidemiol. 2018;28:197-203.

47. Granados A, Gebremariam A, Lee JM. Relationship between timing of peak height velocity and pubertal staging in boys and girls. J Clin Res Pediatr Endocrinol. 2015;7:235-7.

48. Biro FM, Huang B, Crawford PB, Lucky AW, Striegel-Moore R, Barton BA, et al. Pubertal correlates in black and white girls. J Pediatr. 2006;148:234-40.

49. Hemond J, Robbins RB, Young PC. The effects of maternal obesity on neonates, infants, children, adolescents, and adults. Clin Obstet Gynecol. 2016;59:216-27.

50. Li L, Manor O, Power C. Early environment and child-to-adult growth trajectories in the 1958 British birth cohort. Am J Clin Nutr. 2004;80:185-92.

51. Blanchard BA, Hannigan JH. Prenatal ethanol exposure: effects on androgen and nonandrogen dependent behaviors and on gonadal development in male rats. Neurotoxicol Teratol. 1994;16:31-9.

52. Udani M, Parker S, Gavaler J, Van Thiel DH. Effects of in utero exposure to alcohol upon male rats. Alcohol Clin Exp Res. 1985;9:355-9.

53. McGivern RF, Raum WJ, Handa RJ, Sokol RZ. Comparison of two weeks versus one week of prenatal ethanol exposure in the rat on gonadal organ weights, sperm count, and onset of puberty. Neurotoxicol Teratol. 1992;14:351-8.

54. Boggan WO, Randall CL, Dodds HM. Delayed sexual maturation in female C57BL/6J mice prenatally exposed to alcohol. Res Commun Chem Pathol Pharmacol. 1979;23:117-25.

55. Esquifino Al, Sanchis R, Guerri C. Effect of prenatal alcohol exposure on sexual maturation of female rat offspring. Neuroendocrinology. 1986;44:483-7.

56. Grant TM, Huggins JE, Sampson PD, Ernst CC, Barr HM, Streissguth AP. Alcohol use before and during pregnancy in western Washington, 19892004: implications for the prevention of fetal alcohol spectrum disorders. Am J Obstet Gynecol. 2009;200:278 e1-8.

57. Serdula M, Williamson DF, Kendrick JS, Anda RF, Byers T. Trends in alcohol consumption by pregnant women. 1985 through 1988. JAMA. 1991;265:876-9.

58. Brix N, Ernst A, Lauridsen LLB, Parner E, Stovring H, Olsen J, et al. Timing of puberty in boys and girls: a population-based study. Paediatr Perinat Epidemiol. 2019;33:70-8.

\section{Publisher's Note}

Springer Nature remains neutral with regard to jurisdictional claims in published maps and institutional affiliations.

Ready to submit your research? Choose BMC and benefit from:

- fast, convenient online submission

- thorough peer review by experienced researchers in your field

- rapid publication on acceptance

- support for research data, including large and complex data types

- gold Open Access which fosters wider collaboration and increased citations

- maximum visibility for your research: over $100 \mathrm{M}$ website views per year

At BMC, research is always in progress.

Learn more biomedcentral.com/submissions 